\title{
Presence of third molars in orthodontic patients from northern Greece
}

This article was published in the following Dove Press journal:

International Journal of General Medicine

27 May 2012

Number of times this article has been viewed

\section{Georgia Barka' \\ Georgios Tretiakov' \\ Theodosios Theodosiou ${ }^{2}$ \\ loulia loannidou- \\ Marathiotou ${ }^{3}$ \\ 'School of Dentistry, ${ }^{2}$ Biostatistics, Department of Informatics, School of Natural Sciences, ${ }^{3}$ Department of Orthodontics, School of Dentistry, Aristotle University of Thessaloniki, Thessaloniki, Greece}

Objective: The purpose of the present study was to investigate the frequency of presence of third molar teeth and their distribution in each jaw and each side, according to sex, in a group of orthodontic patients with permanent dentition from northern Greece.

Methods: The sample included panoramic radiographs from 220 patients with permanent dentition (mean age $13.62 \pm 1.81$ ). The $\chi^{2}$ test was used to assess the relationships between the variables, and the Fisher's exact test was used in cases where the expected frequencies in each cell were $<5$.

Results: The frequency of third molar presence was $79.1 \%$, and $20.9 \%$ was the frequency of third molar agenesis. Intersexual differences in the number of third molars was not statistically significant. There was a correlation between the distribution of third molars on the right and the left side (Fisher's exact test $=100.788 ; P=0$ ). The two sides showed the same tendency toward the presence or absence of third molars. A correlation was also found between the distribution of maxillary and mandibular third molars (Fisher's exact test $=24.372 ; P=0$ ). In each jaw, the presence or absence of third molars was highly related to the number of third molars found in the other jaw.

Conclusion: The present results showed that in this orthodontic group of northern Greek patients, presence accounted for $79.1 \%$ and agenesis for $20.9 \%$. No significant difference was found between the frequencies of third molar presence on the left and right sides in either the maxilla or mandible.

Keywords: third molars, presence, orthodontic population, Greeks

Third molars (M3s) can be present or absent in the oral cavity. Their presence is characterized by the considerable variability in eruption timing, the level of eruption, and their angular positions. In addition, as they are the last teeth to develop, they are most frequently impacted. Many complications, such as caries and distal root resorption of the adjacent second molar teeth or late crowding of the anterior teeth, have been attributed to the presence of $\mathrm{M} 3 \mathrm{~s}$, which may compromise the results of orthodontic treatment.

The development stage of the M3s has been explored by several authors in different populations. According to Massler et $\mathrm{al}^{1} \mathrm{M} 3$ calcification starts at 7-10 years of age, calcification of the crown is completed at 12-16 years of age, and eruption begins at 17-21 years of age. Garn et $\mathrm{al}^{2}$ reported that the age limit for M3 genesis is 13 years, while Richardson ${ }^{3}$ suggested that M3 genesis may occur up to the age of 16 years old. In Japanese and Israeli populations, ${ }^{4,5}$ it is reported that calcification of M3s begins at approximately 8 years and that the average age for completion of the M3 crowns is 
12 years, while in Spanish children the onset of mandibular M3 formation was observed at very variable ages, ranging from 5.86 to 14.66 years. $^{6}$

To date, the causes of agenesis of one or more M3s are essentially unknown. Several mechanisms have been suggested, such as physical disruption of the dental lamina and the absence of an epithelial signal to the ectomesenchyme, ${ }^{7}$ the failure of a tooth bud to reach a critical size ${ }^{8}$ or more proximately, to receive the signaling to continue development. ${ }^{9}$ Space limitation and crowding are also involved in the agenesis of $\mathrm{M} 3 \mathrm{~s}^{10}$ as well as racial variations in facial growth, jaw size, and tooth size. ${ }^{11}$

The aim of this descriptive study was to investigate the presence of $\mathrm{M} 3 \mathrm{~s}$ in a group of orthodontic patients with permanent dentition from northern Greece. The presence of M3s in each jaw, according to sex, and their relationships were also investigated. It was considered worthwhile to explore the status of $\mathrm{M} 3 \mathrm{~s}$ in this population and to compare the obtained data with the results of previous studies conducted on American, European, and Asian patients.

\section{Methods}

In the present study, we examined the initial panoramic radiographs of orthodontic patients consecutively selected from the archives of the Postgraduate Clinic of the Department of Orthodontics, of the Aristotle University of Thessaloniki, Greece. The radiographs were part of the standard diagnostic records and were taken with the same equipment (Orthopantomograph 10E; Palomex Instrumentarium Corp, Hyryla, Finland).

A total of 618 clinical records were initially examined (274 males and 344 females). These patients had been referred to our clinic from May 25, 1995 to September 14, 2009, and they had either finished or were still receiving orthodontic treatment. All subjects were treated by postgraduate students of the department under the supervision of faculty members.

Inclusion criteria were complete records, ie, medical and dental history, treatment plan, study casts, as well as panoramic and lateral cephalometric radiographs taken before and after treatment. Exclusion criteria were patients with congenital anomalies and syndromes, patients who abandoned the treatment plan or discontinued, and the poor quality of panoramic radiographs.

The group selected comprised 428 patients ( 249 females and 179 males). Two hundred eight patients were noted with mixed dentition, and 220 with permanent dentition. In the present study, the presence of M3s was explored only in patients with permanent dentition $(n=220)$. Third molars refer to both impacted germs and erupted teeth. Signs of crypt formation or crown calcification signified the presence of the corresponding M3 germ. We classified teeth as developmentally missing when no evidence was found in the records that they had been extracted and when no sign of crypt formation or mineralization of the tooth crown was found on the panoramic radiographs.

We examined the number of M3s present per person as well as on the right or the left side in either the maxilla or the mandible and their relationships, for both males and females. The relationship between the distribution of M3s on the right and the left side as well as between the maxilla and the mandible were also evaluated for the total group.

Collected data were subjected to statistical analysis using SPSS software (v 19.0; SPSS Inc, Chicago, IL) and the level of significance for all analyses was set to $\alpha=5 \%$. The $\chi^{2}$ test was used to assess the relationships between our variables. The Fisher's exact test was used in cases where the expected frequencies in each cell were $<5$. The Fisher's exact test allows the computation of the exact probability of the $\chi^{2}$ statistic in such cases. ${ }^{12}$

To check for diagnostic reproducibility, the radiographs of 35 randomly selected patients from the initial 428 of the study were re-evaluated after an 8 -week interval by the same investigator. The McNemar statistical test ${ }^{13}$ showed no statistically significant differences.

\section{Results}

Table 1 shows the descriptive statistics for the patients' age. The mean age of the sample was $13.62 \pm 1.81$ years old.

The distribution of angle malocclusions for each gender is presented in Table 2. The observed differences between females and males in angle classification were not statistically significant.

Table 3 shows the percentage of each M3 $(18,28,38,48)$ for all our patients $(n=220)$ and for each sex as well. In most cases (90.9\%) the upper left M3 was present, followed by the upper right M3 (90\%), lower left M3 (89.5\%), and finally lower right M3 (89.1\%). Higher percentages were recorded for females but based on $\chi^{2}$ statistics this difference was not found to be statistically significant.

The number of M3s found per person is shown in Table 4. All four M3s were found in 174 patients (79.1\%), three M3s

Table I Descriptive statistics for age

\begin{tabular}{llllll}
\hline & $\mathbf{N}$ & Minimum & Maximum & Mean & Std deviation \\
\hline Age & 220 & 9.51 & 18.22 & 13.6233 & 1.81930 \\
\hline
\end{tabular}


Table 2 The results for Angle I, Angle II/1, Angle II/2, Angle II, Angle III, and unclassified malocclusions for each sex, respectively

\begin{tabular}{|c|c|c|c|c|}
\hline & \multicolumn{2}{|l|}{ Sex } & \multirow[t]{2}{*}{ Total } & \multirow[t]{2}{*}{$P$-value } \\
\hline & Male & Female & & \\
\hline \multicolumn{5}{|c|}{ Angle I } \\
\hline No & 72 (32.7\%) & $82(37.3 \%)$ & I 54 (70.0\%) & 0.183 \\
\hline Yes & 24 (10.9\%) & $42(19.1 \%)$ & $66(30.0 \%)$ & \\
\hline \multicolumn{5}{|c|}{ Angle II/1 } \\
\hline No & $48(21.8 \%)$ & 72 (32.7\%) & 120 (54.5\%) & 0.275 \\
\hline Yes & 48 (21.8\%) & $52(23.6 \%)$ & $100(45.5 \%)$ & \\
\hline \multicolumn{5}{|c|}{ Angle II/2 } \\
\hline No & 79 (35.9\%) & $109(49.5 \%)$ & $188(85.5 \%)$ & 0.254 \\
\hline Yes & $17(7.7 \%)$ & $15(7.7 \%)$ & $32(14.5 \%)$ & \\
\hline \multicolumn{5}{|c|}{ Angle II } \\
\hline No & 94 (42.7\%) & 122 (55.5\%) & $216(98.2 \%)$ & I \\
\hline Yes & $2(0.9 \%)$ & $2(0.9 \%)$ & $4(1.8 \%)$ & \\
\hline \multicolumn{5}{|c|}{ Angle III } \\
\hline No & 9I (4I.4\%) & II 3 (5I.4\%) & 204 (92.7\%) & 0.433 \\
\hline Yes & $5(2.3 \%)$ & II (5.0\%) & $16(7.3 \%)$ & \\
\hline \multicolumn{5}{|c|}{ Unclassified } \\
\hline No & $96(43.6 \%)$ & 122 (55.5\%) & $218(99.1 \%)$ & 0.506 \\
\hline Yes & $0(0 \%)$ & $2(0.9 \%)$ & $2(0.9 \%)$ & \\
\hline
\end{tabular}

were found in 19 patients (8.6\%), two M3s were present in 17 patients $(7.7 \%)$, one M3 was present in four patients (1.8\%), and absence of all M3s was found in six patients $(2.7 \%)$. Females have four M3s present more frequently than males, but again no significant difference was found in the number of M3s according to sex $(P=0.313)$.

Table 5 summarizes the figures for patients with none, one, or two M3s present in the maxilla or the mandible and on the left or the right side and the frequencies according to sex. Two maxillary M3s were found in 194 patients (88.2\%), and two mandibular M3s were found in 188 patients (85.5\%). The distribution of M3s was equal for both sides (183 M3s on the right side, $184 \mathrm{M} 3 \mathrm{~s}$ on the left side).

Table 3 The results for third molars 18,28, 38, and 48, respectively

\begin{tabular}{|c|c|c|c|c|}
\hline & \multicolumn{2}{|l|}{ Sex } & \multirow[t]{2}{*}{ Total } & \multirow[t]{2}{*}{$P$-value } \\
\hline & Male & Female & & \\
\hline \multicolumn{5}{|c|}{ Third molar (18) } \\
\hline No & $14(6.4 \%)$ & $8(3.6 \%)$ & $22(10.0 \%)$ & 0.068 \\
\hline Yes & $82(37.3 \%)$ & $116(52.7 \%)$ & 198 (90.0\%) & \\
\hline \multicolumn{5}{|c|}{ Third molar (28) } \\
\hline No & I3 (5.9\%) & 7 (3.2\%) & $20(9.1 \%)$ & 0.058 \\
\hline Yes & $83(37.7 \%)$ & 117 (53.2\%) & $200(90.9 \%)$ & \\
\hline \multicolumn{5}{|c|}{ Third molar (38) } \\
\hline No & $10(4.5 \%)$ & $13(5.9 \%)$ & $23(10.5 \%)$ & I \\
\hline Yes & $86(39.1 \%)$ & III (50.5\%) & I 97 (89.5\%) & \\
\hline \multicolumn{5}{|c|}{ Third molar (48) } \\
\hline No & II (5.0\%) & $13(5.9 \%)$ & 24 (I0.9\%) & 0.831 \\
\hline Yes & 85 (38.6\%) & III (50.5\%) & 196 (89.1\%) & \\
\hline
\end{tabular}

In each gender, the distribution of two M3s was found almost equal for both sides. Two left side M3s were found in 107 females (48.6\%) and 77 males (35.0\%), while two right side M3s were found in 108 females (49.1\%) and 75 males (34.1\%). These differences were not statistically significant. Moreover, two maxillary M3s were found in 115 females (52.3\%) and 79 males (35.9\%), while two mandibular M3s were found in 107 females (48.6\%) and 81 males (36.6). Although the frequency of the presence of M3s in either the maxilla or the mandible was found higher in females than in males, the $\chi^{2}$ statistic revealed no significance.

The distribution of M3s on the right and the left side is depicted in Table 6. Since some cells (four in number) have an expected count $<5$, the Fisher's exact test was used to assess the significance of the relationship (Fisher's exact test $=100.788 ; P<0.001)$. The $\chi^{2}$ statistic revealed a significant relationship, indicating that there is a correlation between the frequencies of M3 existence on the left and the right side. In most patients with both M3s present on the right side, M3s are present on the left side as well (95.1\%). Out of the nine patients who had both right side M3s absent, six of them had both left side M3s absent too (66.7\%), and the rest of them had just one M3 present on the left side (33.3\%). In 28 patients, one right side M3 was absent. In those patients we observed that more frequently one left side $\mathrm{M} 3$ was absent too $(60.7 \%)$, followed by the presence of both M3s on the left side $(35.7 \%)$.

Table 7 shows the distribution of M3s present in the maxilla and the mandible. The $\chi^{2}$ statistic revealed a significant relationship (some cells - four in number - have an expected count $<5$, and the Fisher's exact test was used to assess the statistical significance of the relationship [Fisher's exact test $=24.372 ; P<0.001]$ ), indicating that there is a correlation between the frequencies of present M3s in the upper and the lower jaw. When patients had two maxillary M3s, most of them (89.7\%) had also two mandibular M3s. In cases in which both maxillary M3s were absent, more frequently patients (43.8\%) had two mandibular M3s or none (37.5\%). Patients with one M3 absent from the maxilla, usually have both M3s present in the mandible (70\%) and less frequently $(20 \%)$ one. In the rest $10 \%$ of the cases, both M3s were absent in the mandible.

\section{Discussion}

In the present study based on panoramic radiographs, we attempted to determine the prevalence of $\mathrm{M} 3$ presence in a sample of orthodontic patients from northern Greece. The existence of M3s was investigated in patients with permanent 
Table 4 The number of third molars found per person, in both sexes

\begin{tabular}{|c|c|c|c|c|c|c|c|}
\hline & \multicolumn{5}{|c|}{ Number of third molars } & \multirow[t]{2}{*}{ Total } & \multirow[t]{2}{*}{$P$-value } \\
\hline & None & One & Two & Three & Four & & \\
\hline \multicolumn{8}{|l|}{ Sex } \\
\hline \multicolumn{8}{|l|}{ Male } \\
\hline Patients & 3 & 2 & 9 & 12 & 70 & 96 & 0.313 \\
\hline$\%$ of total & $1.4 \%$ & $0.9 \%$ & $4.1 \%$ & $5.5 \%$ & $31.8 \%$ & $43.6 \%$ & \\
\hline \multicolumn{8}{|l|}{ Female } \\
\hline Patients & 3 & 2 & 8 & 7 & 104 & 124 & \\
\hline$\%$ of total & $1.4 \%$ & $0.9 \%$ & $3.6 \%$ & $3.2 \%$ & $47.3 \%$ & $56.4 \%$ & \\
\hline \multicolumn{8}{|l|}{ Total } \\
\hline Patients & 6 & 4 & 17 & 19 & 174 & 220 & \\
\hline$\%$ of total & $2.7 \%$ & $1.8 \%$ & $7.7 \%$ & $8.6 \%$ & $79.1 \%$ & $100.0 \%$ & \\
\hline
\end{tabular}

dentition in order to evaluate the prevalence of M3 genesis in this population. Third molar presence refers to both impacted germs and erupted teeth. Early extraction of M3s because of dental disease or other eruptive complications was not noticed in our study group. In the present study, females noted higher percentages than males with regard to the presence of each of the four M3s $(18,28,38,48)$, but the intersexual differences were not statistically significant (Table 3). Unfortunately, to our knowledge, published data to make comparisons with our results are lacking. Hence, further research on the presence of each of the four M3s would be worthwhile in order to generate population-specific data and examine further intersexual differences among other populations.

Furthermore, we found that $79.1 \%$ of the subjects had all four M3s, while varying degrees of M3 agenesis were

Table 5 The results for the maxillary and the mandibular third molars, and the right and the left side third molars, for each sex respectively

\begin{tabular}{|c|c|c|c|c|}
\hline & \multicolumn{2}{|l|}{ Sex } & \multirow[t]{2}{*}{ Total } & \multirow[t]{2}{*}{$P$-value } \\
\hline & Male & Female & & \\
\hline \multicolumn{5}{|c|}{ Maxillary } \\
\hline None & $10(4.5 \%)$ & $6(2.7 \%)$ & $16(7.3 \%)$ & 0.054 \\
\hline One & 7 (3.2\%) & $3(1.4 \%)$ & $10(4.5 \%)$ & \\
\hline Two & 79 (35.9\%) & 115 (52.3\%) & 194 (88.2\%) & \\
\hline \multicolumn{5}{|c|}{ Mandibular } \\
\hline None & $6(2.7 \%)$ & 9 (4.1\%) & 15 (6.8\%) & 0.745 \\
\hline One & $9(4.1 \%)$ & $8(3.6 \%)$ & 17 (7.7\%) & \\
\hline Two & 81 (36.6\%) & 107 (48.6\%) & $188(85.5 \%)$ & \\
\hline \multicolumn{5}{|c|}{ Right side } \\
\hline None & $4(1.8 \%)$ & $5(2.3 \%)$ & $9(4.1 \%)$ & 0.154 \\
\hline One & $17(7.7 \%)$ & $11(5.0 \%)$ & $28(12.7 \%)$ & \\
\hline Two & 75 (34.1\%) & $108(49.1 \%)$ & $183(83.2 \%)$ & \\
\hline \multicolumn{5}{|c|}{ Left side } \\
\hline None & $4(1.8 \%)$ & $3(1.4 \%)$ & 7 (3.2\%) & 0.458 \\
\hline One & $15(6.8 \%)$ & $14(6.4 \%)$ & $29(13.2 \%)$ & \\
\hline Two & 77 (35.0\%) & $107(48.6 \%)$ & $184(83.6 \%)$ & \\
\hline
\end{tabular}

noted in the rest (20.9\% of the subjects) (Table 4$)$. These results indicate that about three-quarters of the patients had all four M3s, which is close to the frequency of $76.2 \%$ reported by Kazanci et al ${ }^{14}$ for Turkish patients aged from 12 to 16 years. Our proportion was higher than that reported for the Jordanian ${ }^{15}(72.8 \%)$ and Chinese ${ }^{16}$ populations (71.5\%) and closer to that seen in the Asian-Indian ${ }^{11}(76 \%)$ and Japanese $^{17}$ (77\%) populations. However, our results differ from those reported for another Turkish population with ages ranging from 20 to 26 years where the presence of all four M3s accounted for $63.5 \%{ }^{18}$ and from observations made on Spanish children where it was found that less than one-half of the subjects (38\%) had all four M3s present. ${ }^{6}$ The lower

Table 6 The relationship between the right and the left side third molars, for the total sample

\begin{tabular}{|c|c|c|c|c|c|}
\hline & \multicolumn{3}{|c|}{ Left side third molars } & \multirow[t]{2}{*}{ Total } & \multirow[t]{2}{*}{$P$-value } \\
\hline & None & One & Two & & \\
\hline \multicolumn{6}{|c|}{ Right side third molars } \\
\hline \multicolumn{6}{|c|}{ None } \\
\hline Count & 6 & 3 & 0 & 9 & 0 \\
\hline $\begin{array}{l}\% \text { within right side } \\
\text { third molars }\end{array}$ & $66.7 \%$ & $33.3 \%$ & $0.0 \%$ & $100.0 \%$ & \\
\hline$\%$ of total & $2.7 \%$ & $1.4 \%$ & $0.0 \%$ & $4.1 \%$ & \\
\hline \multicolumn{6}{|l|}{ One } \\
\hline Count & 1 & 17 & 10 & 28 & \\
\hline $\begin{array}{l}\% \text { within right side } \\
\text { third molars }\end{array}$ & $3.6 \%$ & $60.7 \%$ & $35.7 \%$ & $100.0 \%$ & \\
\hline$\%$ of total & $0.5 \%$ & $7.7 \%$ & $4.5 \%$ & $12.7 \%$ & \\
\hline \multicolumn{6}{|l|}{ Two } \\
\hline Count & 0 & 9 & 174 & 183 & \\
\hline $\begin{array}{l}\% \text { within right side } \\
\text { third molars }\end{array}$ & $0.0 \%$ & $4.9 \%$ & $95.1 \%$ & $100.0 \%$ & \\
\hline$\%$ of total & $0.0 \%$ & $4.1 \%$ & $79.1 \%$ & $83.2 \%$ & \\
\hline \multicolumn{6}{|l|}{ Total } \\
\hline Count & 7 & 29 & 184 & 220 & \\
\hline $\begin{array}{l}\% \text { within right side } \\
\text { third molars }\end{array}$ & $3.2 \%$ & $13.2 \%$ & $83.6 \%$ & $100.0 \%$ & \\
\hline$\%$ of total & $3.2 \%$ & $13.2 \%$ & $83.6 \%$ & $100.0 \%$ & \\
\hline
\end{tabular}


Table 7 The relationship between the maxillary and the mandibular third molars, for the total sample

\begin{tabular}{|c|c|c|c|c|c|}
\hline & \multicolumn{3}{|c|}{$\begin{array}{l}\text { Mandibular } \\
\text { third molars }\end{array}$} & \multirow[t]{2}{*}{ Total } & \multirow[t]{2}{*}{$P$-value } \\
\hline & None & One & Two & & \\
\hline \multicolumn{6}{|c|}{ Maxillary third molar } \\
\hline \multicolumn{6}{|l|}{ None } \\
\hline Count & 6 & 3 & 7 & 16 & 0 \\
\hline $\begin{array}{l}\% \text { within maxillary } \\
\text { third molar }\end{array}$ & $37.5 \%$ & $18.8 \%$ & $43.8 \%$ & $100.0 \%$ & \\
\hline$\%$ of total & $2.7 \%$ & $1.4 \%$ & $3.2 \%$ & $7.3 \%$ & \\
\hline \multicolumn{6}{|l|}{ One } \\
\hline Count & $\mathrm{I}$ & 2 & 7 & 10 & \\
\hline $\begin{array}{l}\% \text { within maxillary } \\
\text { third molar }\end{array}$ & $10.0 \%$ & $20.0 \%$ & $70.0 \%$ & $100.0 \%$ & \\
\hline$\%$ of total & $0.5 \%$ & $0.9 \%$ & $3.2 \%$ & $4.5 \%$ & \\
\hline \multicolumn{6}{|l|}{ Two } \\
\hline Count & 8 & 12 & 174 & 194 & \\
\hline $\begin{array}{l}\% \text { within maxillary } \\
\text { third molar }\end{array}$ & $4.1 \%$ & $6.2 \%$ & $89.7 \%$ & $100.0 \%$ & \\
\hline$\%$ of total & $3.6 \%$ & $5.5 \%$ & $79.1 \%$ & $88.2 \%$ & \\
\hline \multicolumn{6}{|l|}{ Total } \\
\hline Count & 15 & 17 & 188 & 220 & \\
\hline $\begin{array}{l}\% \text { within maxillary } \\
\text { third molar }\end{array}$ & $6.8 \%$ & $7.7 \%$ & $85.5 \%$ & $100.0 \%$ & \\
\hline$\%$ of total & $6.8 \%$ & $7.7 \%$ & $85.5 \%$ & $100.0 \%$ & \\
\hline
\end{tabular}

proportion of M3 presence in the later study may be attributed to the very young age of the patients they included in their study (their sample ranged from 4 to 20 years old). Higher frequency of M3 germs was reported for black Americans compared to white Americans. ${ }^{19}$ These racial differences are interesting and suggest that some polygenetic inheritance on formation of M3 germs may differ among populations and races.

According to our results, it is most common for four M3s to be present (79.1\%), followed by three (8.6\%), two (7.7\%), none $(2.7 \%)$, and one (1.8\%) (Table 4$)$. The same tendency was noted for the Turkish ${ }^{14,18}$ and Asian-Indian ${ }^{11}$ populations. Nevertheless, studies performed in Jordanian, ${ }^{15} \mathrm{Czech},{ }^{20}$ and Spanish $^{6}$ patients showed different results with regard to the order of frequency of present M3s.

The incidence of just one of any of the M3s congenitally missing in our study group occurred in $20.9 \%$, which is significantly lower than that reported for Spanish children $(62 \%)^{6}$ and lower but closer to that recorded for the Chinese population $(28.5 \%) .{ }^{16}$ In contrast, our results were significantly higher than that recorded for Czech patients $(10.9 \%) .{ }^{20}$ Interestingly, percentages recorded in the present study were very close to the data reported by Kazanci et a ${ }^{14}$ for a Turkish population (23.8\%), suggesting that the prevalence and distribution of M3s in the Turkish population show the same tendency with the Greeks.
Intersexual comparisons revealed no significant differences in the incidence of M3 agenesis, despite the higher percentage noted for males than that for females (11.8\% and $9.1 \%$, respectively) (Table 4 ). The male predominance of M3 agenesis agrees with the results reported for Jordanian students ${ }^{15}$ but differs from data reported for Turkish ${ }^{18}$ and Asian-Indian ${ }^{11}$ populations. However, all the above-mentioned investigators concluded that intersexual differences were not statistically significant, which is in agreement with our findings. No significance was also reported for the Turkish, ${ }^{14,21}$ Chinese, ${ }^{16}$ Japanese, ${ }^{17}$ and Spanish ${ }^{6}$ populations.

On the other hand, Rozkovcová et $\mathrm{a}^{20,22}$ and Liu et $\mathrm{al}^{23}$ reported that the intersexual differences were statistically significant, with $\mathrm{M} 3$ agenesis being more common in men than in women. A greater male-female difference was also found in whites compared to blacks. ${ }^{19}$ In blacks the frequencies of agenesis were not statistical different, but in whites a statistical difference was found. White females were 1.8 times as likely to have a missing mandibular M3 than males. ${ }^{19}$

According to the results of a survey conducted by Daito et $\mathrm{al}^{4}$ in Japanese people, $9.5 \%$ of the males and $12 \%$ of the females had no M3s. In contrast, in our study the agenesis of all M3s was found significantly lower and equal for both sexes (1.4\%) (Table 4). The number of absent M3s was also evaluated for both sexes in a Czech population, and the authors reported that in males, the most frequent agenesis was of one, next of two, then of three, and last of four M3s, while in females, agenesis of two was in first place, then that of one, and last and equal of three and of four M3s. ${ }^{20}$ Our observations, however, showed different frequencies of agenesis in both sexes. In males, it was most common for one M3 to be absent, followed by two, four, and three, while in females in most cases there was agenesis of two M3s, next of one, then of four, and last of three M3s (Table 4).

The incidence of M3 agenesis was found equal for both sides in our study (Table 5). Hence, our findings are in accordance with data reported by many other investigators who showed that the differences between the two sides were not significant. ${ }^{11,14-17,23}$ Moreover, according to our results no sexual dimorphism was found in the number of M3s between the two sides (Table 5). These data may indicate a genetic trend for no predilection in the agenesis of M3s regarding the sides in both males and females.

Studies performed in different populations demonstrate that the majority of missing M3s were located in the maxilla, with the differences being statistically significant. ${ }^{14,16,17,21}$ Hattab et $\mathrm{al}^{15}$ and Sandhu and Kaur ${ }^{11}$ also reported that congenitally 
missing M3s showed a greater predilection for the maxilla over the mandible. They found that bilateral agenesis of M3s in the maxilla compared to the mandible was higher with a ratio of $2: 1$ and $3: 1$, respectively. ${ }^{11,15}$ In the present study, the ratio for the bilateral agenesis of $\mathrm{M} 3 \mathrm{~s}$ in the maxilla compared to the mandible was approximately 1:1 (Table 5). Moreover, no significant difference was found between the frequencies of at least one M3 missing in the maxilla and the mandible. Our results may indicate a population-specific feature for this Mediterranean race, but further studies need to be conducted in wider samples of the Greek population to support our findings.

In the present study, the $\chi^{2}$ statistic revealed a significant relationship indicating that there was a correlation between the distribution of $\mathrm{M} 3 \mathrm{~s}$ on the left and the right side (Table 6) (Fisher's exact test $=100.788 ; P=0$ ). When both M3s were present on the right side, M3s were present on the left side as well. Accordingly, when both right side M3s were absent, both left side M3s were more frequently absent too. Lastly, when one M3 was found on the one side, another one was found on the opposite side as well. These findings suggest that the two sides show the same tendency toward the presence or absence of M3s.

Additionally, a correlation was also found between the distribution of maxillary and mandibular M3s (Fisher's exact test $=24.372 ; P=0)$ (Table 7). It seems that in each jaw, the presence or absence of $\mathrm{M} 3 \mathrm{~s}$ is highly related to the number of M3s found on the other jaw. When one M3 is found in either the maxilla or the mandible, most frequently two M3s are expected to be found in the other jaw, and when two M3s are present in either the maxilla or the mandible, two M3s are also expected to be present in the other jaw.

\section{Conclusion}

The present results showed that in this orthodontic population from northern Greece, M3 presence accounted for 79.1\% and M3 agenesis for $20.9 \%$. Differences with other studies were noticed with regard to the frequencies of missing M3s in the upper and lower arches. According to these reports, the frequency of M3 agenesis was found greater in the upper jaw, while in our study no significant difference was found between the frequencies of M3 presence in the maxilla and the mandible. Such differences among studies of the prevalence of $\mathrm{M} 3 \mathrm{~s}$ performed in different populations may be attributed to differences in sample sizes, statistical methods, diagnostic criteria, and the selection of the target population. Environmental and genetic etiological factors may also explain these deviations. Therefore, variations in the prevalence of M3s seem to be inevitable among different populations.

\section{Disclosure}

The authors report no conflicts of interest in this work.

\section{References}

1. Massler M, Schour I, Poncher HG. Developmental pattern of the child as reflected in the calcification pattern of the teeth. Am J Dis Child. 1941;62(1):33-67.

2. Garn SM, Lewis AB, Vicinus JH. Third molar agenesis and reduction in the number of other teeth. J Dent Res. 1962;41(3):717.

3. Richardson M. Late third molar genesis: its significance in orthodontic treatment. Angle Orthod. 1980;50(2):121-128.

4. Daito M, Tanaka T, Hieda T. Clinical observations on the development of third molars. J Osaka Dent Univ. 1992;26(2):91-104.

5. Sarnat H, Kaffe I, Porat J, Amir E. Developmental stages of the third molar in Israeli children. Pediatr Dent. 2003;25(4):373-377.

6. Bolaños MV, Moussa H, Manrique MC, Bolaños MJ. Radiographic evaluation of third molar development in Spanish children and young people. Forensic Sci Int. 2003;133(3):212-219.

7. Tucker AS, Al Khamis A, Sharpe PT. Interactions between Bmp-4 and Msx-1 act to restrict gene expression to odontogenic mesenchyme. Dev Dyn. 1998;212(4):533-539.

8. Fitzgerald LR. Deciduous incisor teeth of the mouse (Mus musculus). Arch Oral Biol. 1973;18(3):381-389.

9. Keränen SV, Kettunen P, Aberg T, Thesleff I, Jernvall J. Gene expression patterns associated with suppression of odontogenesis in mouse and vole diastema regions. Dev Genes Evol. 1999;209(8):495-506.

10. Stewart RE, Barber TK, Thoutman KC, Wei Shy. Pediatric Dentistry: Scientific Foundation and Clinical Practice. 1st ed. St, Louis, IL: Mosby; 1982.

11. Sandhu S, Kaur T. Radiographic evaluation of the status of third molars in the Asian-Indian students. J Oral Maxillofac Surg. 2005; 63(5):640-645.

12. Field A. Discovering Statistics using SPSS for Windows. 3rd ed. London, UK: Sage Publications; 2009.

13. Durkalski VL, Palesch YY, Lipsitz SR, Rust PF. Analysis of clustered matched-pair data. Stat Med. 2003;22(2):2417-2418.

14. Kazanci F, Celikoglu M, Miloglu O, Oktay H. Third-molar agenesis among patients from the East Anatolian region of Turkey. $J$ Contemp Dent Pract. 2010;11(4):E033-E040.

15. Hattab FN, Rawashdeh MA, Fahmy MS. Impaction status of third molars in Jordanian students. Oral Surg Oral Med Oral Pathol Oral Radiol Endod. 1995;79(1):24-29.

16. Mok YY, Ho KK. Congenitally absent third molars in 12 to 16 year old Singaporean Chinese patients: a retrospective radiographic study. Ann Acad Med Singapore. 1996;25(6):828-830.

17. Kajii T, Imai T, Kajii S, Iida J. Presence of third molar germs in orthodontic patients in Japan. Am J Orthod Dentofacial Orthop. 2001; 119(3):245-250.

18. Celikoglu M, Miloglu O, Kazanci F. Frequency of agenesis, impaction, angulation, and related pathologic changes of third molar teeth in orthodontic patients. J Oral Maxillofac Surg. 2010;68(5):990-995.

19. Harris EF, Clark LL. Hypodontia: an epidemiologic study of American black and white people. Am J Orthod Dentofacial Orthop. 2008; 134(6): $24-29$.

20. Rozkovcová E, Marková M, Lánik J, Zvárová J. Agenesis of third molars in young Czech population. Prague Med Rep. 2004;105(1):35-52.

21. Topkara A, Sari Z. Prevalence and distribution of hypodontia in a Turkish orthodontic patient population: results from a large academic cohort. Eur J Paediatr Dent. 2011;12(2):123-127.

22. Rozkovcová E, Marková M, Láník J, Zvárová J. Development of third molar in the Czech population. Prague Med Rep. 2004;105(4): 391-422.

23. Liu XQ, Sun XY, Chen J, Liu J, Xu H, Fan CH. A statistic analysis on absence of third molar germs in orthodontic patients. Hua Xi Kou Qiang Yi Xue Za Zhi. 2004;22(6):493-495. 
International Journal of General Medicine

Dovepress

\section{Publish your work in this journal}

The International Journal of General Medicine is an international, peer-reviewed open-access journal that focuses on general and internal medicine, pathogenesis, epidemiology, diagnosis, monitoring and treatment protocols. The journal is characterized by the rapid reporting of reviews, original research and clinical studies across all disease areas.
A key focus is the elucidation of disease processes and management protocols resulting in improved outcomes for the patient. The manuscript management system is completely online and includes a very quick and fair peer-review system. Visit http://www.dovepress.com/ testimonials.php to read real quotes from published authors.

Submit your manuscript here: http://www.dovepress.com/international-journal-of-general-medicine-journal 